\title{
MOBILITY AND EQUIPMENT FOR THE VENTILATOR-DEPENDENT TETRAPLEGIC
}

\author{
By Lola M. Dingemans, B.S., O.T.R. and J. MagGie Hawn, B.S., O.T.R. \\ Department of Occupational Therapy, Craig Hospital, Rocky Mountain Regional Spinal \\ Cord Center, 3425 South Clarkson, Englewood, Colorado, U.S.A.
}

\section{Introduction}

To realistically rehabilitate persons surviving spinal cord injures ventilator assistance, rehabilitation specialists need to provide programmes to mobilise and equip these individuals. The ventilator-dependent tetraplegic comprises the smallest group of patients, yet ironically require the most financial, emotional and professional effort to return to an active life.

A team approach centring around single physician direction and encouraging early family participation has provided a programme for approximately 60 ventilator-dependent tetraplegics over a 5-year period. Ideally, early referral to a spinal cord centre comfortable with the ventilator-dependent tetraplegics' needs will increase the potential for overall medical management and optimal rehabilitation (Hahn, 1977). The following represents our present approach to realistically, physically mobilise and equip ventilator-dependent tetraplegics.

\section{Early Mobility}

\section{Mobility}

Halo vest immobilisation enables resumption of the upright position within the Ist month after resolution of acute medical problems and satisfactory respiratory support. 'Mobility and assuming upright is the single most important factor in reducing respiratory complications in the ventilator-dependent quadraplegic' (Roper, 1977). Early mobility allows movement to other treatment areas of the hospital which encourages contact with other patients and decreases severe physical and environmental isolation. Family members are actively involved in these initial stages of the programme and begin learning techniques for his mobilisation.

Initially, the occupational and physical therapists use the tilt table, progressing the ventilator-dependent tetraplegic to the reclining wheelchair. Dependent side-to-side weight shifts enable extended wheelchair sitting periods, building general endurance and physiological adaptation needed to meet the programme demands.

\section{Ventilator Dependency: Weaning}

During early mobility, certain criteria are used to determine if the person can be independent from ventilator support. Physiological feasibility and psychological readiness establishes success of weaning (Roper, 1977). If freedom from the ventilator is not a goal, short periods of time off ventilator are attempted and encouraged as a safety margin in the event of electro-mechanical failure and to provide psychological balance. It is helpful to be reminded that the mobility and weaning programme are both physically and emotionally energy consuming.

A well coordinated team can more adequately cope with equipment frustrations and move the bedside ventilator equipment to the treatment areas. As early 
as possible during the programme, portable ventilator equipment is introduced to assure easier continued mobility in the hospital and at home.

\section{Continuing Mobility}

As the ventilator-dependent tetraplegic progresses in his early sitting and weaning programme, he participates in individual mat exercises with his therapist (Fig. I). He experiences severe loss of body and special awareness and often is

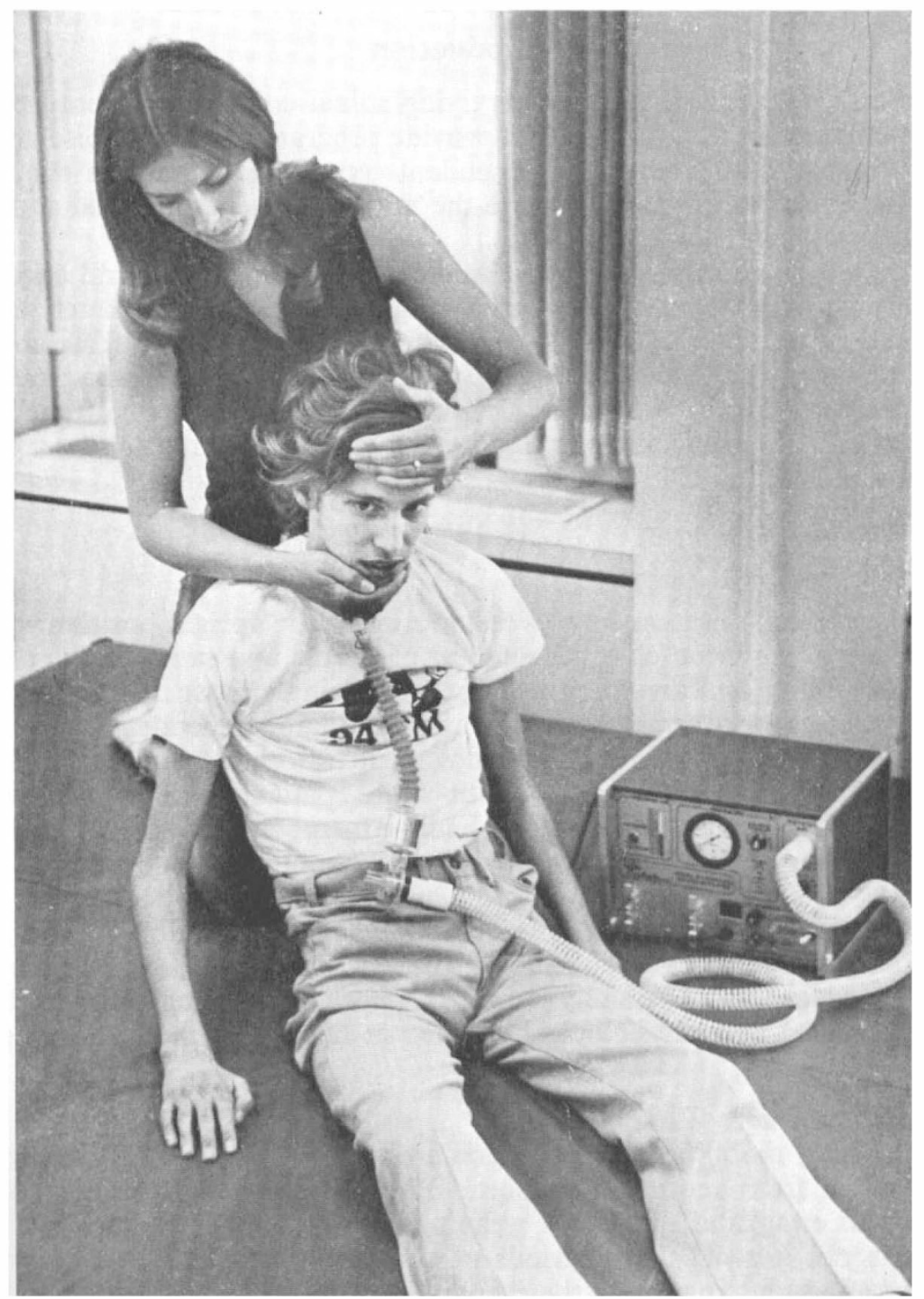

FIG. I

Dependent on the portable $\mathrm{LP}_{3}$ ventilator, a $\mathrm{C}_{2}$ tetraplegic participates in his daily mat exercise programme with the therapist. The programme often begins while he is in halo vest immobilisation and using his bedside ventilator equipment. 
fearful and anxious of handling and movement. Providing normal vestibular input, increasing neck muscle strength and a sense of balance encourages trust in his therapist and eliminates much of his fear and anxiety.

$\mathrm{He}$ is included in a group mat exercise class with quadriplegics at all levels of injuries to work on stretching and body-shifting techniques in preparation for standard wheelchair transfers. The ventilator-dependent tetraplegic joins other spinal cord injured persons in another class to learn to instruct aides to move him in the electric and manual chair, overcome architectural barriers and handle the chairs on smooth and outdoor terrain. Exercises to increase his neck range of motion, sitting balance, and strength assures more effective control of the electric chair.

\section{Mobility Outside the Hospital}

When the ventilator-dependent tetraplegic has sufficient sitting tolerance, adequate portable ventilator support, and psychological readiness, he is introduced to life outside the hospital. The occupational or respiratory therapist will accompany him on outings to a shopping centre, movie, restaurant or bar. In this way, he is re-exposed to the community in an informal yet enjoyable way, encouraged to experience the same situations which may occur when he is discharged from the hospital to his home. He gains experience in instructing attendants or family members in techniques of moving his body, portable ventilator and suctioning equipment outside the hospital.

A large number of the ventilator-dependent tetraplegics live too far from the hospital to go on weekend passes but are able to spend I week or more in the facility's apartments for an independent living experience with their family or attendants.

\section{Transfers}

Moving the ventilator-dependent tetraplegic and his equipment from his wheelchair, bed or to an automobile seat is simplified for one person by using sliding board transfers. The physical therapist instructs the patient and family members in the proper transfer technique thus eliminating mechanical lifts (Figs. 2 and 3).

\section{Equipment for the Ventilator-dependent Tetraplegic}

The spinal cord team attempts to equip the ventilator-dependent tetraplegic to achieve the goal of mobility. When properly chosen, the equipment allows more privacy and freedom to manipulate his environment, improves his self concept, and reduces attendant care. The team provides equipment and encourages him to explore and attempt all vocational and avocational options within his environmental and intellectual limitations. (See Appendix for equipment sources.)

Equipment is introduced as early as possible in the programme for psychological and physical reasons. It has been our experience that persons who have some means of controlling their environment early in their rehabilitation programme have a better personal acceptance of the equipment. The ventilatordependent tetraplegic may receive some of his equipment during re-evaluation hospitalisations.

It is often helpful to ask the following questions when equipping the ventilatordependent tetraplegic. 

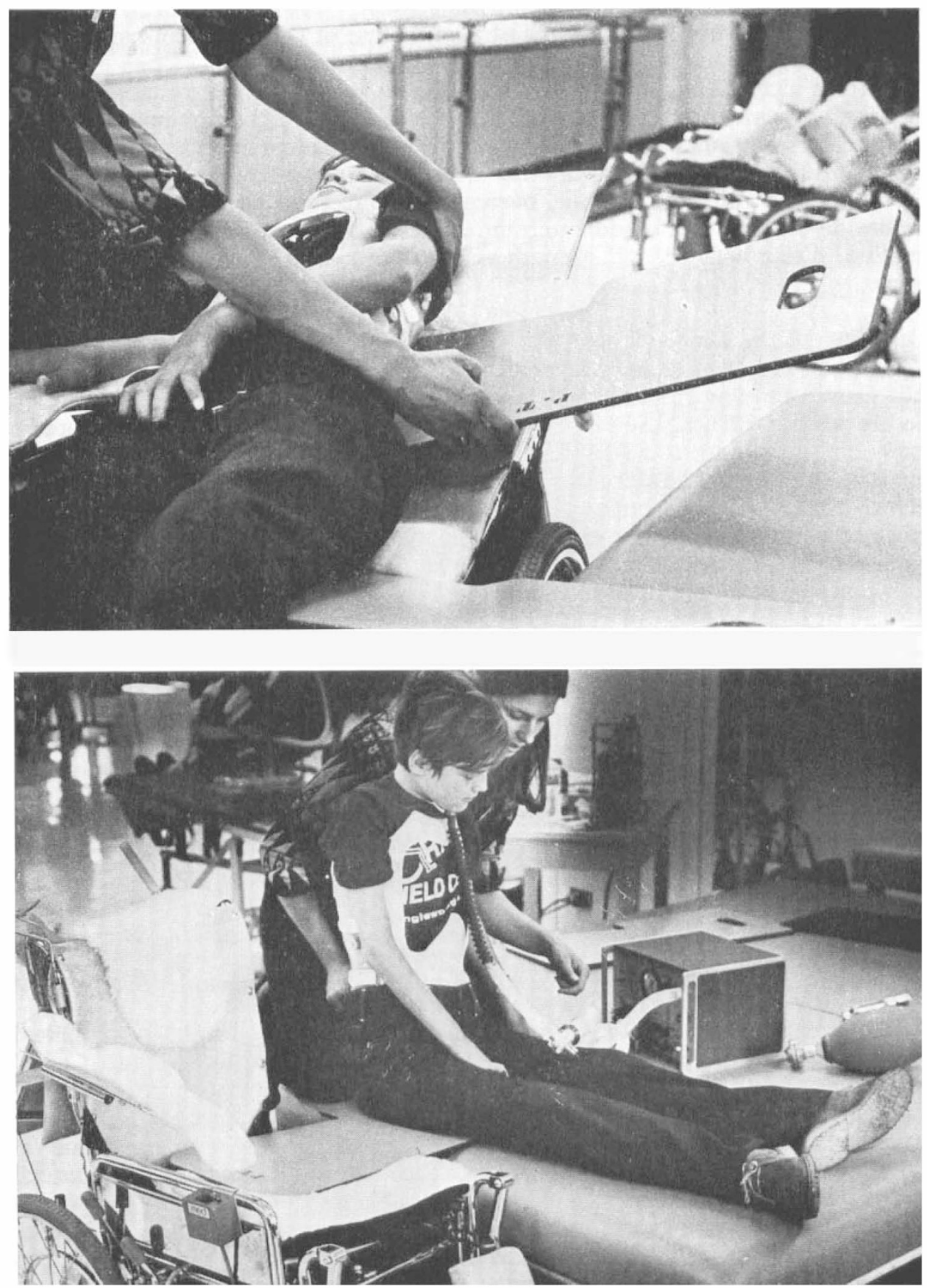

FIGS. 2 and 3

Using one or two transfer boards, one person is able to safely move the ventilator-dependent tetraplegic without a mechanical lift. (Fig. 2) A C3 tetraplegic performs a single board sliding transfer to his Falcon Reclining Power Wheelchair with breath controls. (Fig. 3)

Placement of two transfer boards for a flat transfer from the wheelchair is illustrated. 
I. What are the available funds?

2. What are the environmental limitations at home, school and vocational settings?

3. Who will be responsible for his care?

4. Are vocational, recreational, emotional, and cultural needs met?

5. Is there access to easy repair and maintenance ?

6. Is there a personal acceptance or rejection to the equipment?

\section{Portable Ventilator Equipment}

Each ventilator-dependent tetraplegic is discharged with three ventilator systems: the bedside unit, the portable ventilator equipment and the ambo bag which accompanies him everywhere. The portable ventilator and suctioning units are the most important equipment for mobility in and out of the wheelchair. The Thompson Mini Lung and Life Products $\mathrm{LP}_{3}$ are compact, easily moved volume pressure ventilators which have proven the most successful. The portable Laerdal Suction Unit and the ventilators run on self-contained batteries for I to 2 hours or can be plugged into wall electric outlets, wheelchair or automobile batteries.

\section{Electric Wheelchairs}

The ventilator-dependent tetraplegic and his occupational therapist begin exploration and evaluation of electric wheelchairs early in the mobility programme. There are four specific areas to consider for equipping the wheelchair:

I. Ventilator adaptions for wheelchairs: the electric wheelchair battery is adapted with a jack to accommodate the portable ventilator equipment. Falcon Research has modified a chair, the Falcon Reclining Respirator Chair, to contain the ventilator and suction unit in a tray under the chair seat. A second successful option is to provide a lapboard designed to transport the ventilator in front of the person on both the manual and electric chair.

2. Wheelchair controls: controlling the electric wheelchair is often the first exciting successful experience of independent movement the ventilator-dependent tetraplegic experiences. He chooses the chair controls that are best adapted for him after testing each method. The chin or tongue control wheelchair has many variations and is easily operated by persons with good head control and sitting stability. The chin control can be independently moved out of the way by the patient to allow performance of mouthstick, transfer or other activities. Another system, the sip and puff breath switch control has proven as popular as the chin control, especially for the younger more aggressive patient or those who lack head control.

The DU-IT wheelchair control systems and the optic control are being evaluated and may increase the options available for our patients.

3. Recline systems: an independently operated recline system on the electric chair encourages a full 8-hour day in the wheelchair and enables weight shifts for pressure relief. A full recline position provides rest periods which reduce the number of bed to chair transfers and increases options for activities outside the home or domicillary facility. The ventilator dependent tetraplegic controls his recline system by a reduced pressure or a sip and puff breath control switch mounted on the chair or infrequently on a neck collar.

Three types of electric reclining systems which can be independently controlled have been used by our ventilator-dependent tetraplegics. The Everest and Jennings electric reclining wheelchair modified with a Falcon Reclining Kit is 
light-weight and easily handled outdoors. A head rest moves into place as the the chair reclines and a sliding seat cushion reduces sheering forces on the skin. A second poular recline option is the Everest and Jennings Reclining Wheelchair with a Med-cliner unit without a sliding seat or drop-away headrest. The Independence Chair (Rugg Chair) with the same sliding seat and head rest features as the Falcon Chair is not often purchased yet may be appropriate for some patients.

4. Body stabilisation: it is important to consider individual needs for stability and balance in the wheelchair when evaluating trunk, leg or head supports. Various pieces of equipment often are custom designed to eliminate specific positioning problems. Cushioned sliding arm troughs with forearm straps support the arms and hands when the chair is moving or reclining. They are easily removed to accommodate sliding board transfers. Elevating leg rests raise as the wheelchair reclines to allow full resting position and reduce stasis and oedema. Calf and foot troughs or straps may be chosen to maintain leg positions. Lateral trunk supports, corsets, and waist and chest belts are evaluated for maintaining body alignment. The tetraplegic who is unable to develop muscle strength or who experiences abnormal brain stem reflexes may require customised head supports.

\section{Manual Wheelchair}

A full recline manual wheelchair adapted for body stabilisation and ventilator equipment is necessary to provide mobility to areas inaccessible to the electric wheelchair or in the event of electric wheelchair failure.

\section{Environmental Control Equipment}

Independently controlling a chair increases the ventilator-dependent tetraplegic's options for using other pieces of equipment. The following equipment has been successfully adapted in our programme.

Lapboards are devised to be sturdy, light-weight, adjustable in height, easily removable and serve multiple needs for work areas or transporting equipment.

Mouthsticks and adjustable holding units enable the ventilator-dependent tetraplegic to be self-reliant in a variety of activities (Fig. 4). A light-weight mouthpiece, which is fitted by a dental professional, provides protection of teeth, allows speaking when in place, and independent placement and removal (Blaine, 1973; Frankel, 1975).

Environmental control units which have been adapted to our institution are evaluated by each patient. Due to the expense and maintenance requirements, very few units have been used successfully in the home environment for any extended period of time (Green, 1974). Currently, a variety of new control systems are being evaluated for home, school and vocational use.

Typewriters, tape recorders, and pageholders are chosen and adapted for use with the mouthstick. Adapted telephone systems can be operated by a mouthstick, incorporated into the environmental control units, or provided by local telephone companies throughout the United States.

\section{Travel}

Transportation of the ventilator-dependent tetraplegic outside the hospital is made easier by teaching transfers and providing adaptations for safe travelling in a regular passenger car. A van with adaptations to allow easy entry and travel safety can be considered for the person in the electric wheelchair. 


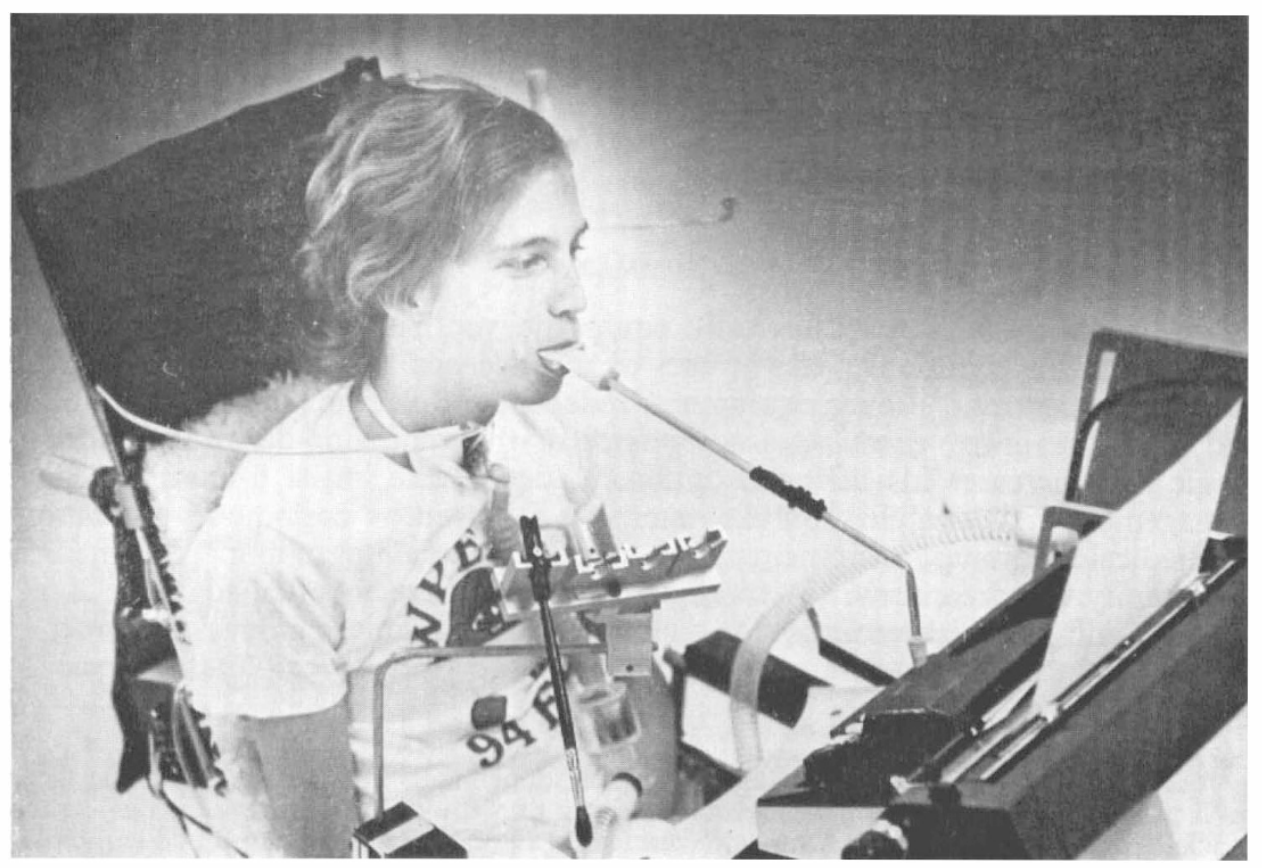

FIG. 4

A C2 tetraplegic uses a temporary mouthpiece with a Med-Mouthstick and Holder Kit.

\section{Case History}

The following brief case history illustrates one ventilator-dependent tetraplegic's experience in our programme and represents several variations from the ideal rehabilitation situation. Paul K. is a $2 \mathrm{I}$-year-old male with a $\mathrm{C}_{3}$ fracture dislocation injured in a work-related fall, 7 September 1976 . It is significant to know he was treated at a local general hospital, immobilised with Vinke Tongs and was transferred to Craig Hospital by private plane 20 December 1976. Medical diagnosis and functional status upon admission was:

I. Tetraplegia, $\mathrm{C}_{2}$ last preserved segment.

2. Respiratory insufficiency requiring tracheotomy and full-time ventilator assistance.

3. Upper motor neurogenic bowel and bladder requiring suprapubic catheter.

4. Decubitis on right heel.

5. Status post-chest injury healed.

Paul's young, pregnant wife was actively involved in his entire programme and delivered their first child before his discharge. Double-bed accommodations were provided for them in the hospital which appeared to give Paul added incentive for active participation in the programme.

Repeated attempts at weaning for short periods of time were not successful and Paul concentrated on mat exercises, standing and transfer activities, and evaluating and choosing equipment. Periodic depressions slowed his sitting ability progress yet Paul was tolerating 8-Io hours in his electric wheelchair when he went home. Paul's parents were unable to emotionally accept responsibility for his physical care but financed many pieces of equipment.

Two months after his programme began, Paul ordered a Falcon Reclining Respirator 
Chair, $\mathrm{LP}_{3}$ Ventilator, Laerdal Portable Suction, mouthstick, and van. Before discharge to his home, Paul lived in Craig's apartments for 2 weeks with wife, child and parents. On I4 April 1977 Paul was discharged with plans to live with his family and parents in a wheelchair-accessible house before continuing his education. Paul will return in 6 months for medical follow-up, equipment and functional upgrading, and respiratory status evaluation.

\section{SUMMARY}

The opportunity to realistically equip the ventilator-dependent tetraplegic to return to his community can be met by a concerned team in specialised spinal cord injury centres. Proper equipment, independent electric wheelchair mobility and family training, encourages acceptance of the ventilator-dependent quadriplegic and increases his life-style options. Ideally, the initial 6-month medical management and rehabilitation programme is followed by periodic re-evaluations for medical follow-up, equipment changes and functional upgrading. The medical community must continue to respond to the challenge to offer adequate living facilities and financial resources for equipment and programme development.

\section{RÉSUMÉ}

La possibilité d'équiper le tétraplégic qui est dépendant d'un ventilateur d'une façon qu'il puisse rentrer chez lui peut être réalisée par une équipe concernée dans des centres specialisés dans les blessures du vertèbre cervicale. De l'équipement propre, de la mobilité indépendante achevée par un fauteuil roulant électrique, et enfin l'inclusion de la famille du patient encouragent l'acceptation du tétraplégic qui est dépendant d'un ventilateur, et augmentent ses options de vie. Au cas idéal, la période initiale qui consiste du traitement médical ainsi que du programme de réhabilitation, et qui dure 6 mois, est suivie par des contrôles périodiques, c'est-à-dire des examens médicaux, des modifications d'équipement, et du perfectionnement fonctionnel. La communauté médicale doit continuer à repondre à la nécessité d'offrir des ressources de vie adéquats et les finances nécessaires pour de l'équipement et le developpement de programmes.

\section{ZUSAMMENFASSUNG}

Die Möglichkeit, den Ventilator-abhängigen an allen vier Gliedmassen Gelähmten auf eine Weise auszustatten, welche ihm die Wiedereingliederung in die Gesellschaft ermöglicht, kann durch ein Spezialistenteam in Spezialzentren für Rückenmarksverletzungen praktisch verwirklicht werden. Geeignete Apparaturen, freie Beweglichkeit durch einen elektrischen Rollstuhl and Einbeziehung der Familie fördern die Akzeptierung des an allen vier Gliedmassen gelähmten und Ventilator-abhängigen Patienten innerhalb der Gesellschaft und vermehren die Möglichkeiten seiner Lebensführung. Im Idealfall folgen auf die ursprüngliche Phase von 6 Monaten, bestehend aus der medizinischen Behandlung und dem Rehabilitationsprogramm, in periodischen Abständen Uberprüfungen für medizinische Nachuntersuchungen, Apparaturen-Modifizierungen und funktionelle Verbesserungen. Die medizinische Öffentlichkeit muss fortfahren, der Forderung nach adäquaten Lebenseinrichtungen und Geldmitteln für die Entwicklung von Apparaturen und Programmen durch entsprechende Angebote nachzukommen.

Acknowledgement. We thank Earl Roper, R.R.T., Dr R. Menter, Sue Levin, O.T.R., and members of the Media and Occupational Therapy Departments of Craig Hospital for their assistance.

\section{REFERENCES}

Blaine, H. L. \& Nelson, E. P. (1973). A mouthstick for quadriplegic patient, Fournal of Prosthetic Dentistry, 29, 3 I 7. 
Frankel, M. A. (1975). A new pattern mouthstick. Paraplegia, 13, 66.

GrEen, R. (1974). The current status of and future consideration for environmental control systems. Bulletin of Prosthetic Research, Fall, 3 IO.

HAHN, H. R. (1977). Emergency management of the patient with spinal cord injury. Resident and Staff Physician fournal, 23, 50.

Roper, E. (I977). Considerations of respiratory function in cervical cord injuries. Paper presented in Englewood, Colorado.

\section{APPENDIX: Equipment Sources}

Chin, Tongue Wheelchair Controls

Custom Lap Boards for Reclining Chairs

Med Mouthstick, Holder, and Adjustable Clamp Kits

Med-cliner Recliner Units

Reclining Arm Rest Units

Wheelchairs, Inc.

Dick DeVoe, President

3400 South Corona

Englewood, Colorado 801 Io

DU-IT Wheelchair Control Systems

Romich, Beery, and Bayer, Inc.

Electronic Design Manufacturing and Consulting

R.D.2, Box I9I

Shreve, Ohio 44676

Electric and Manual Recline Wheelchairs

Everest and Jennings, Inc.

Robert Birch, Vice President

I803 Pontius Avenue

Los Angeles, California 90025

Environmental Control Systems

Prentke Romich Company

R.D.2, Box I9I

Shreve, Ohio 44676

Falcon Power Reclining Systems

Independence Chair (Rugg Chair)

Swing-Away Chin Control

Falcon Research and Development

Alden C. Simmons, Marketing Manager

I 225 South Huron

Denver, Colorado 80223
Laerdal Portable Suction Unit Laerdal Medical Corporation I36 Marbledale Road

Tuckahoe, New York 10707

Life Products $\mathrm{LP}_{3}$ Portable Ventilator

P.O. Box 3370

Life Products, Inc.

Boulder, Colorado 80303

Sip n' Puff Switches

Medical Equipment Distributors, Inc.

Charles Chevillon, President

I2 I5 South Harlem Avenue

Forest Park, Illinois 60130

Thompson Mini Lung Portable Ventilator Thompson Respiration Products, Inc. I925 55th Street Boulder, Colorado 80303

Telephone Adaptations

Rehabilitation Monograph XXXV

Telephone Services for the Handicapped Publications Department Institute of Rehabilitation Medication 400 E. 34th Street

New York, New York IooI6 